\title{
Optimal dynamic pricing and replenishment policies for deteriorating items
}

\author{
Masoud Rabbani*, Nadia Pourmohammad Zia and Hamed Rafiei
}

School of Industrial Engineering, College of Engineering, University of Tehran, Tehran, Iran

C H R O N I C L E A B S T R A C T

\begin{tabular}{l}
\hline Article history: \\
Received January 222014 \\
Received in Revised Format \\
June 62014 \\
Accepted June 182014 \\
Available online \\
June 23 2014 \\
\hline Keywords: \\
Dynamic pricing \\
Replenishment \\
Advertisement \\
Time-dependent deterioration rate
\end{tabular}

\begin{abstract}
Marketing strategies and proper inventory replenishment policies are often incorporated by enterprises to stimulate demand and maximize profit. The aim of this paper is to represent an integrated model for dynamic pricing and inventory control of deteriorating items. To reflect the dynamic characteristic of the problem, the selling price is defined as a time-dependent function of the initial selling price and the discount rate. In this regard, the price is exponentially discounted to compensate negative impact of the deterioration. The planning horizon is assumed to be infinite and the deterioration rate is time-dependent. In addition to price, the demand rate is dependent on advertisement as a powerful marketing tool. Several theoretical results and an iterative solution algorithm are developed to provide the optimal solution. Finally, to show validity of the model and illustrate the solution procedure, numerical results are presented.
\end{abstract}

\section{Introduction}

Dynamic pricing is the process of changing price during a period due to variations in stock level, demand level, inventory quality, etc. It is one of the most efficient tools of the revenue management, which enhances ability of the firms in managing demand and making profit. In recent years, this marketing strategy has been widely used by industries (Coy, 2000) due to three main reasons including emergence of a very competitive environment in businesses and industries, increasing access to demand information, and ease of applying price changes due to advent of new technologies. In classic inventory control models, it is assumed that the goods can be held infinitely for future demand, while such assumption does not hold in reality as the majority of the products lose their original value as time passes and for some of them this happens more quickly (Khanlarzade et al., 2014). These products are called deteriorating items. In inventory management problems, deterioration is defined as damage, putrefaction, demolition, evaporation, expiration, and reduction of efficiency and margin value of product, which lead to a decrease in product serviceability (Yang \& Wee, 2003). Medicine, fruits and vegetables, seasonal and temporary products, and electronic devices are common examples of deteriorating items. Since deterioration results in a drop in quality and stock-level of the inventory, it imposes additional costs on the inventory system. Therefore, efficient inventory control of deteriorating items is of great importance.

* Corresponding author. Tel: +982188335605

E-mail: mrabani@ut.ac.ir (M. Rabbani)

(C) 2014 Growing Science Ltd. All rights reserved.

doi: $10.5267 /$ j.ijiec. 2014.6 .002 
Previously, pricing and inventory management policies were incorporated separately; however integration of these two policies enhances the profit of the firms through coordination of supply and demand. Integrated decision making on inventory management and pricing decisions for deteriorating products is a branch of revenue management, which has attracted many researchers working in inventory management, economy, marketing and operations research areas. In this study an integrated model for dynamic pricing and inventory control of deteriorating products is developed. To tackle the practical conditions of the inventory systems, not only the deterioration rate changes over time, but also the selling price is assumed to be time-dependent. In addition, the demand rate is dependent on advertisement, which is modeled as the frequency of advertisement in each cycle. To characterize the optimal solution, some useful theoretical results are derived based on which an iterative and simple solution algorithm is developed.

The remainder of the paper is organized as follows: In section 2, the literature body of the problem is briefly reviewed and the related research gaps are distinguished. The assumptions and notations of the model are presented in section 3. In section 4, the mathematical model of the inventory system is formulated. Section 5 provides the theoretical results and the solution algorithm, which are applied to obtain the optimal solution. Numerical results are represented in section 6 . Finally section 7 , finishes the paper with conclusion and recommended future research directions.

\section{Literature review}

Dynamic pricing and inventory control of deteriorating items have attracted a great deal of academic attention. Thus, there exists a wide-spread literature in this area, which is briefly reviewed as follows. In the context of the discussed problem, the first model was proposed by Cohen (1977). In this paper, demand was price-dependent and the deterioration rate is assumed to be constant. This paper was extended in Kang and Kim (1983) by considering a finite replenishment rate. Abad (2003) conducted one of the noble researches in the field of pricing. In the proposed economic production quantity model, demand was defined as a general function of selling price. This model is studied by Yang (2004) for economic order quantity problem. Teng et al. (2007) extended Abad's model by incorporating shortage cost and cost of lost reputation. For the first time, Wee (1997) proposed a timedependent deterioration rate which followed Weibull distribution. The proposed model was extended in Wee (1999) by adding discount option for purchasing cost and modeling shortage in the form of partial backlog. Papachristos and Skouri (2003) extended the model of Wee (1999) by considering demand as a general, convex, and descending function of price, modeling shortage in form of time-dependent backlog, and modifying the revenue function. Mukhopadhyay et al. $(2004,2005)$ are other worth mentioning research instances with similar structures. Tsao and Sheen (2008) presented one of the rare studies on effect of advertisement on demand. Demand was considered as a linear function of price, exponential function of time and quadratic function of the cost of the advertisement. Shah et al. (2013) incorporated advertisement into the demand model as well. In their paper advertisement is modeled as the frequency of advertisement in each replenishment cycle.

Begum et al. (2009) developed an instantaneous replenishment policy for deteriorating items with price-dependent demand. They applied a three-parameter Weibull distribution to present timedependency of inventory deterioration rate. Begum et al. (2012) conducted another study on the previous model by neglecting shortage and assuming demand as a non-linear function of price. Cai et al. (2013) proposed one of the very few researches on dynamic pricing which modeled price as a function of time. Optimal policy was obtained by considering the feedback of the price on demand per time unit. To validate the proposed structure, a numerical simulation was employed. Wang et al. (2013) also considered price as a function of time and modeled a non-instantaneous deterioration pattern. In this context, Geetha and Uthayakumar (2010), Valliathal and Uthayakumar (2011), Maihami and Abadi (2012), Ghoreishi et al. (2013) and Soni and Patel (2012,2013) studied non-instantaneous deterioration 
as well. Dye et al. (2007) Considered an economic order quantity model where demand and deterioration rate were continuous functions of price and time, respectively. Shortage was possible and completely backlogged. In Dye (2007), some extensions have been made by assuming partial backlog rate as an exponential function and a reverse function of remained time. Abad (2008) studied a model with similar structure and considered partial backlog rate as a general descending function of the remained time to the next review of the inventory system. Soni and Joshi (2013) proposed a framework for pricing and inventory control of deteriorating items under bi-level trade credit in fuzzy settings.

Considering time-dependent deterioration rate as well as price and time dependent demand rate simultaneously, forms a more complicated variation of pricing problems, which has not been investigated sufficiently. Hsu et al. (2007) modeled the deterioration rate as a general function of time. A seasonal pattern was assumed for demand, which was time and price-dependent. Uncertain delivery time, backlogging and limited budget are some of the assumptions in the proposed model. Hsieh and Dye (2010) presented an inventory control model for deteriorating items under inflation. The model was solved by descending cash flow method. In addition, demand rate was dependent to time and price and shortage was partially backlogged. Shah and Raykandaliya (2010) considered demand as a decreasing function of price and time and assumed Weibull distribution for deterioration rate. Tripathy and Pradhan (2011) proposed a similar model but considered a three-parameter Weibull distribution for deterioration rate. Dye (2012) modeled demand as a general decreasing function of time and price. Purchasing price and product deterioration rate were defined as general functions of time. Finite time horizon and partial time-dependent backlog were considered in the structure of the proposed model. Delayed payment provided by both supplier and retailer is incorporated in the model as well. Avinadav et al. (2013) also provided a mathematical model with price and time-dependent demand for perishable items.

Coming up to a conclusion, there exist number of research gaps: Firstly in the area of dynamic pricing, there are few studies formulating price as a function of time by defining discount variable, while this study has formulated the selling price as a time-dependent function by defining discount fraction variable as well as initial price. Secondly, in spite of the high significance of advertisement in stimulating demand, there are few related research works linking demand to the advertisement factor. In this study, the advertisement factor is modeled as the frequency of advertisement in each replenishment cycle.

\section{Notations and assumptions}

\section{Notations}

\section{Parameters}

$\begin{array}{cl}c & \text { The constant purchasing cost per unit } \\ h & \text { The holding cost per unit per time unit } \\ k & \text { The ordering cost per order } \\ G & \text { Cost of each advertisement } \\ \theta(t) & \text { The deterioration rate } \\ \text { ariable } & \\ A & \text { The frequency of advertisement in each cycle (decision variable) } \\ p(t) & \text { The dynamic price of product per unit at any time } t \text { (decision variable) } \\ T & \text { The replenishment cycle of the product (decision variable) } \\ I(t) & \text { The inventory level at time } t \\ Q & \text { The order quantity } \\ O C & \text { The total ordering cost } \\ H C & \text { The total inventory holding cost } \\ P C & \text { The total purchasing cost }\end{array}$




$\begin{array}{cl}A C & \text { The total advertisement cost } \\ D C & \text { The total disposing cost } \\ T P(p(t), A, T) & \text { The total profit per time unit of the inventory system }\end{array}$

\section{Assumptions}

1. The replenishment rate and planning horizon are infinite.

2. The lead time is zero and shortage is not allowed.

3. The inventory system involves single deteriorating item.

4. The dynamic price of the product at time $t$ is modeled as: $p(t)=p_{0} \exp (-\sigma t)$ where $p_{0}$ is the initial price and $\sigma \in \pi$ is discount variable for each time unit passing after the start of deterioration. In this paper we have considered $\pi=\{0.2,0.5,0.8\}$ naming low, medium and high discount rates.

5. The demand rate is a function of the selling price and frequency of advertisement, which is formulated as $D(p(t), A)=(M B-\omega p(t))(1+A)^{\lambda}$ where $M B$ is the potential demand where price is equal to zero, $\omega>0$ is the price sensitivity factor and $0 \leq \lambda<1$ is the shape parameter of the advertisement.

6. The deterioration rate $\theta(t)$ at any time $t \geq 0$ follows Weibull distribution given by $\alpha \beta t^{\beta-1}$. Where $0<\alpha \leq 1$ is the scale parameter and $\beta>0$ is the shape parameter. In this paper we have assumed $\beta=2$.

\section{The mathematical formulation}

The inventory system evolves as follows: $Q$ units arrive at the inventory system at the beginning of each cycle. Then inventory level declines due to demand and deterioration during time interval $[0, T]$. Based on this description, during time interval $[0, T]$ the inventory status is represented by the following differential equation:

$$
\frac{d I_{2}(t)}{d t}=-D(p(t), A)-\theta(t) I(t) \quad 0 \leq t \leq T
$$

With boundary condition $I(T)=0$ solving Eq. (1) yields:

$$
I(t)=e^{-\alpha t^{2}} \int_{t}^{T} D(p(u), A) e^{\alpha u^{2}} d u \quad 0 \leq t \leq T
$$

Therefore the order quantity is equal to:

$$
Q=I(0)=\int_{0}^{T} D(p(u), A) e^{\alpha u^{2}} d u
$$

The total profit of the inventory system involves the following components:

1. SR: The sales revenue

$$
S R=\int_{0}^{T} p(t) D(p(t), A) d t
$$

2. OC: The ordering cost $O C=k$

3. HC: The inventory holding cost 


$$
H C=h \int_{0}^{T} I(t) d t=h \int_{0}^{T} e^{-\alpha t^{2}} \int_{t}^{T} D(p(u), A) e^{\alpha u^{2}} d u d t
$$

4. PC: The purchasing cost

$$
P C=c Q=c\left(\int_{0}^{T} D(p(u), A) e^{\alpha u^{2}} d u\right)
$$

5. AC: The advertisement cost

$$
A C=G A
$$

Therefore, the total profit per time unit $(T P(p(t), A, T))$ is given by:

$$
T P(p(t), A, T)=\frac{1}{T}(S R-O C-H C-P C-A C)
$$

\section{Solution methodology}

Since the formulated equations are complex, the concavity of the total profit per time unit cannot be proved by using Hessian matrix. Therefore, the problem is solved applying the following search procedure which is similar to ones used in Wu et al. (2009) and Shah et al. (2013) as well. We first prove that for given values of $\sigma, p_{0}$ and $T$ there exist a unique optimal value of $A$. Then for fixed values of $\sigma, p_{0}$ and $A$, a unique optimal value of $T$ is obtained and finally, for fixed $\sigma, A$ and $T$, a unique optimal value of $p_{0}$ is determined which maximizes the total profit per time unit. Since the discount fraction is defined as a discrete variable, the above mentioned procedure is applied for different values of $\sigma$ and finally the optimal solution is obtained by comparing the results. Firstly, for fixed $\sigma, p_{0}$ and $T$, the second order derivative of $T P(p(t), A, T)$ is obtained as follows:

$$
\frac{\partial^{2} T P}{\partial A^{2}}=\frac{\lambda(\lambda-1)(1+A)^{\lambda}}{T}(\text { Expression } 1)
$$

where:

$$
\begin{aligned}
& \text { Expression } 1=\text { Expression } a-\text { Expression } b-\text { Expression } c \\
& \text { Expression } a=\int_{0}^{T}\left(M B-\omega p_{0}\left(e^{-\sigma t}\right)\right) p_{0}\left(e^{-\sigma t}\right) d t \\
& \text { Expression } b=h \int_{0}^{T}\left(e^{-\alpha t^{2}}\right) \int_{t}^{T}\left[\left(M B-\omega p_{0}\left(e^{-\sigma u}\right)\right)\left(e^{\alpha u^{2}}\right) d u\right] d t \\
& \text { Expression } c=c \int_{0}^{T}\left(M B-\omega p_{0}\left(e^{-\sigma t}\right)\right)\left(e^{\alpha t^{2}}\right) d t
\end{aligned}
$$

Since $\lambda<1$ it is obvious that $\frac{\partial^{2} T P}{\partial A^{2}}<0$, therefore $T P(p(t), A, T)$ is a concave function of $A$ and the search to find the optimal frequency of advertisement is restricted to find a local optimum. Now some useful theoretical results are derived in order to find the optimal length of replenishment $\left(T^{*}\right)$ and the optimal initial price $\left(p_{0}{ }^{*}\right)$ for two aforementioned possible cases.

Lemma 1. For fixed $A$ and $p_{0}$ there exists a unique $T^{*}$ which maximizes $T P(p(t), A, T)$.

Proof. The first order partial derivative of $T P(p(t), A, T)$ with respect to $T$ is given by

$$
\frac{\partial T P}{\partial T}=\frac{\left(S R^{\prime}-H C^{\prime}-P C^{\prime}\right) T-(S R-O C-H C-P C-A C)}{T^{2}}
$$

where: 


$$
\begin{aligned}
& S R^{\prime}=p_{0}(1+A)^{\lambda}\left(e^{-\sigma T}\right)\left(M B-\omega p_{0}\left(e^{-\sigma T}\right)\right) \\
& H C^{\prime}=h(1+A)^{\lambda}\left(M B-\omega p_{0}\left(e^{-\sigma T}\right)\right)\left(e^{\alpha T^{2}}\right) \int_{0}^{T} e^{-\alpha t^{2}} d t \\
& P C^{\prime}=c(1+A)^{\lambda}\left(M B-\omega p_{0}\left(e^{-\sigma T}\right)\right)\left(e^{\alpha T^{2}}\right)
\end{aligned}
$$

Motivated by Eq. (15) the auxiliary function $R(T)$ is defined as:

$$
R(T)=\left(S R^{\prime}-H C^{\prime}-P C^{\prime}\right) T-(S R-O C-H C-P C-A C)
$$

The first order derivative of $R(T)$ with respect to $T \in\left[t_{d}, \infty\right)$ gives:

$$
\frac{d R(T)}{d T}=\left(S R^{\prime \prime}-H C^{\prime \prime}-P C^{\prime \prime}\right) T
$$

where:

$$
\begin{aligned}
& S R^{\prime \prime}=-\sigma p_{0}(1+A)^{\lambda} e^{-\sigma T}\left(M B-2 \omega p_{0} e^{-\sigma T}\right) \\
& H C^{\prime \prime}=h(1+A)^{\lambda}\left\{\begin{array}{l}
{\left[2 \alpha T e^{\alpha T^{2}}\left(M B-\omega p_{0}\left(e^{-\sigma T}\right)\right)+\sigma \omega p_{0}\left(e^{-\sigma T}\right)\left(e^{\alpha T^{2}}\right)\right] \int_{0}^{T}\left(e^{-\alpha t^{2}}\right) d t} \\
\left(M B-\omega p_{0}\left(e^{-\sigma T}\right)\right)
\end{array}\right\} \\
& P C^{\prime \prime}=c(1+A)^{\lambda}\left[\begin{array}{l}
\left.2 \alpha T e^{\alpha T^{2}}\left(M B-\omega p_{0}\left(e^{-\sigma T}\right)\right)+\sigma \omega p_{0}\left(e^{-\sigma T}\right)\left(e^{\alpha T^{2}}\right)\right]
\end{array}\right.
\end{aligned}
$$

It is shown that $R(T)$ is a strictly decreasing function, moreover from Eq. (19) it follows that:

$$
\begin{gathered}
R(0)=k+A G>0 \\
\text { and } \lim _{T \rightarrow \infty} R(T)=-\infty
\end{gathered}
$$

Applying the intermediate value theorem, there exist a unique value of $T\left(\operatorname{say} T^{*} \in[0, \infty)\right.$ ) where $R(T)=0$ which means that $T^{*}$ is the unique solution of $\frac{\partial T P(p(t), A, T)}{\partial T}=0$.

From Eq. (15) and Eq. (19) we have

$$
\frac{\partial T P(p(t), A, T)}{\partial T}=\frac{R(T)}{T^{2}}
$$

Since $R(T)$ is strictly decreasing (i.e. $\left.\frac{d R(T)}{d T}=\left(S R^{\prime \prime}-H C^{\prime \prime}-P C^{\prime \prime}\right) T<0\right)$ we have:

$$
\left.\frac{\partial^{2} T P(p(t), A, T)}{\partial T^{2}}\right|_{T=T^{*}}=\frac{\left(S R^{\prime \prime}-H C^{\prime \prime}-P C^{\prime \prime}\right)}{T}<0
$$

Therefore, There exist a unique global maximum solution of $\operatorname{TP}(p(t), A, T)$.

Lemma 2. For fixed $A$ and $T$ there exists a unique $p_{0}{ }^{*}$, which maximizes $\operatorname{TP}(p(t), A, T)$.

Proof. The first order derivative of $T P(p(t), A, T)$ with respect to $p_{0}$ gives

$$
\frac{\partial T P}{\partial p_{0}}=(1+A)^{\lambda}\left\{M B \int_{0}^{T} e^{-\sigma t} d t-2 \omega p_{0} \int_{0}^{T} e^{-\sigma t} d t+h \omega \int_{0}^{T}\left(e^{-\alpha t^{2}}\right) \int_{t}^{T_{1}}\left(e^{\alpha u^{2}}\right)\left(e^{-\sigma u}\right) d u d t+c \omega \int_{0}^{T}\left(e^{\alpha t^{2}}\right)\left(e^{-\sigma t}\right) d t\right.
$$


By solving $\frac{\partial T P}{\partial p_{0}}=0, p_{0}^{*}$ yields

$$
p_{0}^{*}=\left\{M B \int_{0}^{T^{*}} e^{-\sigma t} d t+h \omega \int_{0}^{T^{*}}\left(e^{-\alpha t^{2}}\right) \int_{t}^{T^{*}}\left(e^{\alpha u^{2}}\right)\left(e^{-\sigma u}\right) d u d t+c \omega \int_{0}^{T^{*}}\left(e^{\alpha t^{2}}\right)\left(e^{-\sigma t}\right) d t\right\} /-2 \omega \int_{0}^{T^{*}} e^{-\sigma t} d t
$$

At point $p_{0}=p_{0}^{*}$

$$
\left.\frac{\partial^{2} T P}{\partial p_{0}^{2}}\right|_{p_{0}=p_{0}^{*}}=-2 \omega(1+A)^{\lambda} \int_{0}^{T^{*}} e^{-\sigma t} d t+h \omega
$$

$\left.\frac{\partial^{2} T P}{\partial p_{0}{ }^{2}}\right|_{p_{0}=p_{0}^{*}}<0$. Thus $p_{0}^{*}$ is the global optimum solution for fixed $A$ and $T^{*} \in[0, \infty)$.

Remark. For fixed $A$ and $\sigma$ the unique optimal solution for $\left(T, p_{0}\right)$ which maximizes $T P(p(t), A, T)$ exists. The optimal solution can be obtained through some iterative numerical procedure. Based on the concavity of the objective function, the following algorithm which is similar to the one proposed by Wu et al. (2009) is developed to identify global optimal solution for $\left(A, p_{0}, \sigma, T\right)$.

\section{Algorithm}

Step 1: Set $j=1$ and $\sigma=0.2$.

Step 2: Set $A^{j}=0$.

Step 3: Set $k=1$ and initialize the value of $p_{0}{ }^{k, j}=c$.

Step 4: Obtain the value of $T^{k, j}$ by solving $\frac{\partial T P(p(t), A, T)}{\partial T}=0$. Substitute $T^{k, j}$ into Equation (27)in order to calculate $p_{0}{ }^{k, j}$. Set $p_{0}{ }^{k+1, j}=p_{0}{ }^{k, j}$.

Step 5: If $\left|p_{0}{ }^{k+1, j}-p_{0}{ }^{k, j}\right|<$ Epsilon (Epsilon is considered to be a very small value), then set $\left(p_{0}{ }^{j^{*}}, T^{j^{*}}\right)=\left(p_{0}{ }^{(k+1, j)^{*}}, T^{(k, j)^{*}}\right)$ and go to Step 6. Otherwise, $k=k+1$ and go back to Step 4 .

Step 6:Calculate $\operatorname{TP}\left(p(t)^{j^{*}}, A^{j}, T^{j^{*}}\right)$, then $\left(p_{0}{ }^{j^{*}}, T^{j^{*}}\right)$ is the optimal solution and $\operatorname{TP}\left(p(t)^{j^{*}}, A^{j}, T^{j^{*}}\right)$ is the maximum value of the objective function for fixed $A^{j}$ and $\sigma$.

Step 7: Set $A^{j}=A^{j}+1$ and repeat Step 3 to Step 6 to obtain $\operatorname{TP}\left(p(t)^{j^{*}}, A^{j^{j}}, T^{j^{*}}\right)$.

Step 8:If $T P\left(p(t)^{j^{*}}, A^{j}, T^{j^{*}}\right)>T P\left(p(t)^{j^{*}}, A^{j}, T^{j^{*}}\right)$, then $A^{j}=A^{j}$ and go back to Step 7. Otherwise go to Step 9.

Step 9: Set $\left(p_{0}{ }^{j^{*}}, A^{j^{*}}, T^{j^{*}}\right)=\left(p_{0}{ }^{j^{*}}, A^{j}, T^{j^{*}}\right)$ which is the optimal solution for fixed $\sigma$.

Step 10: Set $j=j+1$ and $\sigma=\sigma+0.3$. If $\sigma \leq 0.8$ go back to Step 2; otherwise go to Step 11 .

Step 11: Set $T P\left(p(t)^{p^{*}}, A^{p}, T^{p^{*}}\right)=\max _{j}\left\{T P\left(p(t)^{j^{*}}, A^{j}, T^{j^{*}}\right)\right\}$ and $\left(p_{0}^{*}, \sigma^{*}, A^{*}, T^{*}\right)=\left(p_{0}^{p^{*}}, \sigma^{p^{*}}, A^{p^{*}}, T^{p^{*}}\right)$.

Step 12: End

\section{Experimental results}

In this section, the developed algorithm is applied to solve the following problem in order to show validity of the proposed model and applicability of the developed algorithm. The values of the parameters of the problem are defined in Table 2. Identical parameters of model are taken from Shah et al. (2013) and adopted to our model. The expanded results of the executed procedure of the proposed 
algorithm are represented in Table 3. In order to show the effect of related deterioration and advertisement parameters, Table 4 provides the computational results for different values of $\alpha$ and $\lambda$.

Table 2

The value of the parameters of the problem

\begin{tabular}{lllllllll}
\hline Parameter & $M B$ & $\omega$ & $k$ & $G$ & $h$ & $c$ & $\alpha$ & $\lambda$ \\
\hline Value & 300 & 12 & 250 & 80 & 0.4 & 3 & 0.75 & 0.04 \\
\hline
\end{tabular}

Table 3

Illustration of solution procedure of the proposed algorithm

\begin{tabular}{cccccc}
\hline$\sigma$ & $A$ & $p_{0}$ & $T$ & $Q$ & $T P$ \\
\hline \multirow{3}{*}{0.2} & 0 & 4.2221 & 0.5199 & 197.5145 & 9719.384 \\
& 1 & 4.2485 & 0.5525 & 202.8615 & 10098.724 \\
& 2 & 4.2714 & 0.5705 & 208.7295 & 10217.574 \\
& 3 & 4.3108 & 0.6283 & 240.1519 & 10187.446 \\
\hline 0.5 & 0 & 4.7874 & 0.5798 & 190.1285 & 10864.274 \\
& 1 & 4.8217 & 0.5979 & 212.0535 & 11359.493 \\
& 2 & 4.8522 & 0.6248 & 228.4295 & 11560.514 \\
& 3 & 4.8794 & 0.6305 & 242.5535 & 11636.628 \\
& 4 & 4.9294 & 0.6585 & 266.7615 & 11611.554 \\
\hline 0.8 & 0 & 5.5495 & 0.5766 & 197.4795 & 12593.551 \\
& 1 & 5.5814 & 0.5865 & 216.4575 & 13233.156 \\
& 2 & 5.6103 & 0.5955 & 230.0738 & 13523.818 \\
& 3 & 5.6370 & 0.6039 & 241.3152 & 13666.859 \\
& 4 & 5.6620 & 0.6118 & 251.1525 & 13727.742 \\
\hline
\end{tabular}

Table 4

Computational results for different values of $\alpha$ and $\lambda$

\begin{tabular}{cccccccc}
\hline$\alpha$ & $\lambda$ & $\sigma$ & $A$ & $p_{0}$ & $T$ & $Q$ & $T P$ \\
\hline \multirow{2}{*}{0.3} & 0.03 & 0.8 & 3 & 5.6011 & 0.6425 & 257.4321 & 13742.143 \\
& 0.04 & 0.8 & 5 & 5.9921 & 0.6642 & 270.3246 & 14417.142 \\
& 0.05 & 0.8 & 9 & 6.3348 & 0.7121 & 286.5532 & 14705.132 \\
0.45 & 0.03 & 0.8 & 3 & 5.4771 & 0.6374 & 242.5512 & 13579.439 \\
& 0.04 & 0.8 & 5 & 5.8012 & 0.6513 & 264.8742 & 14227.169 \\
& 0.05 & 0.8 & 9 & 6.2189 & 0.7003 & 285.1327 & 14502.045 \\
0.6 & 0.03 & 0.8 & 3 & 5.4581 & 0.6213 & 234.8765 & 13327.912 \\
& 0.04 & 0.8 & 5 & 5.6991 & 0.6426 & 252.4384 & 14013.762 \\
0.75 & 0.05 & 0.8 & 9 & 6,0872 & 0.6821 & 277.1132 & 14313.261 \\
& 0.03 & 0.8 & 3 & 5.4327 & 0.6107 & 220.3471 & 13181.654 \\
& 0.04 & 0.8 & 5 & 5.6855 & 0.6392 & 260.0795 & 13736.595 \\
\hline
\end{tabular}

Based on the computational results, following managerial insights are obtained about deterioration and advertisement factors which are analogous to Shah et al. (2013):

1. For fixed $\alpha$, increasing $\lambda$ causes an increase in optimal replenishment cycle $\left(T^{*}\right)$, optimal order quantity $\left(Q^{*}\right)$, optimal advertisement frequency $\left(A^{*}\right)$, optimal initial price $\left(p_{0}^{*}\right)$ and total profit per time unit of the inventory system $(T P)$. Increasing the shape of advertisement $(\lambda)$ increase $A^{*}$ and therefore, results in an increase in demand and the total profit of the system. The optimal discount fraction $\left(\sigma^{*}\right)$ is not sensitive to changes in $\lambda$.

2. For fixed $\lambda$, with an increase in the value of $\alpha$, optimal advertisement frequency $\left(A^{*}\right)$ and optimal discount fraction $\left(\sigma^{*}\right)$ remain unchanged, while increasing $\alpha$ results ina decrease in the value of optimal order quantity $\left(Q^{*}\right)$ and total profit per time unit of the inventory system ( $T P$ ). In comparison to the other variables, changes in the value of optimal initial price $\left(p_{0}{ }^{*}\right)$ is 
imperceptible. It can be concluded that, implementing better inventory preservation technologies lowers the effect of deterioration and enhances the total profit of the inventory system.

\section{Conclusion}

Coordination of inventory management and marketing policies play an important role in maximizing profit of firms. In this paper, we proposed an integrated model for dynamic pricing and inventory control of non-instantaneous deteriorating items. The selling price was defined as a time-dependent function of the initial price and discount rate, which is one of the noble features of the proposed model. In addition to price, the demand rate was a function of advertisement as a powerful marketing tool. In spite of the high significance of advertisement in stimulating demand, there exist few related research works linking demand to the advertisement factor. In this study, the advertisement factor was modeled as the frequency of advertisement in each cycle. An iterative algorithm was developed based on derived theoretical results. We illustrated through the experimental results the way the optimal solution was obtained. Computational results indicated that increasing the impact of the deterioration decreases total profit of the inventory system, which was due to the imposed costs on the system. Therefore, implementing better inventory preservation technologies can efficiently enhance the profit of the system by lowering the negative effect of the deterioration. The proposed model can be extended by considering shortages, trade credit and time value of money. Considering non-instantaneous deterioration pattern is another future research direction.

\section{References}

Abad, P. L. (2003). Optimal pricing and lot-sizing under conditions of perishability, finite production and partial backordering and lost sale. European Journal of Operational Research, 144(3), 677-685.

Abad, P. L. (2008). Optimal price and order size under partial backordering incorporating shortage, backorder and lost sale costs. International Journal of Production Economics, 114(1), 179-186.

Avinadav, T., Herbon, A., \& Spiegel, U. (2013). Optimal Inventory Policy for a Perishable Item with Demand Function Sensitive to Price and Time. International Journal of Production Economics, 144(2),497-506.

Begum, R., Sahoo, R. R., Sahu, S. K., \& Mishra, M. (2009). An EOQ Model for Varying Items with Weibull Distribution Deterioration and Price-dependent Demand. Journal of Scientific Research, 2(1), 24-36.

Begum, R., Sahoo, R. R., \& Sahu, S. K. (2012). A replenishment policy for items with price-dependent demand, time-proportional deterioration and no shortages. International Journal of Systems Science, 43(5), 903-910.

Cai, X., Feng, Y., Li, Y., \& Shi, D. (2013). Optimal pricing policy for a deteriorating product by dynamic tracking control. International Journal of Production Research, 51(8), 2491-2504.

Cohen, M. A. (1977). Joint pricing and ordering policy for exponentially decaying inventory with known demand. Naval Research Logistics Quarterly, 24(2), 257-268.

Coy, P. (2000). The power of smart pricing. Business week, (April 10), 160.

Dye, C. Y. (2007). Joint pricing and ordering policy for a deteriorating inventory with partial backlogging. Omega, 35(2), 184-189.

Dye, C. Y. (2012). A finite horizon deteriorating inventory model with two-phase pricing and time-varying demand and cost under trade credit financing using particle swarm optimization. Swarm and Evolutionary Computation, 5, 37-53.

Dye, C. Y., Hsieh, T. P., \& Ouyang, L. Y. (2007). Determining optimal selling price and lot size with a varying rate of deterioration and exponential partial backlogging. European Journal of Operational Research, 181(2), 668-678.

Geetha, K. V., \& Uthayakumar, R. (2010). Economic design of an inventory policy for non-instantaneous deteriorating items under permissible delay in payments. Journal of Computational and Applied Mathematics, 233(10), 2492-2505.

Ghoreishi, M., Mirzazadeh, A., \& Weber, G. W. (2013). Optimal pricing and ordering policy for noninstantaneous deteriorating items under inflation and customer returns. Optimization, (ahead-of-print), 1-20.

Hsieh, T. P., \& Dye, C. Y. (2010). Pricing and lot-sizing policies for deteriorating items with partial backlogging under inflation. Expert Systems with Applications, 37(10), 7234-7242. 
Hsu, P. H., Wee, H. M., \& Teng, H. M. (2007). Optimal ordering decision for deteriorating items with expiration date and uncertain lead time. Computers \& Industrial Engineering, 52(4), 448-458.

Kang, S., \& Kim, I. T., (1983). A study on the price and production level of the deteriorating inventory system. The International Journal of Production Research, 21(6), 899-908.

Khanlarzade, N., Yegane, B. Y., Kamalabadi, I. N., \& Farughi, H. (2014). Inventory control with deteriorating items: A state-of-the-art literature review. International Journal of Industrial Engineering Computations, 5(2), 179-198.

Maihami, R., \&Abadi, I. N. K. (2012). Joint control of inventory and its pricing for non-instantaneously deteriorating items under permissible delay in payments and partial backlogging. Mathematical and Computer Modelling, 55(5), 1722-1733.

Mukhopadhyay, S., Mukherjee, R. N., \& Chaudhuri, K. S. (2004). Joint pricing and ordering policy for a deteriorating inventory. Computers \& Industrial Engineering, 47(4), 339-349.

Mukhopadhyay, S., Mukherjee, R. N., \& Chaudhuri, K. S. (2005). An EOQ model with two-parameter Weibull distribution deterioration and price-dependent demand. International Journal of Mathematical Education in Science and Technology, 36(1), 25-33.

Papachristos, S., \& Skouri, K. (2003). An inventory model with deteriorating items, quantity discount, pricing and time-dependent partial backlogging. International Journal of Production Economics, 83(3), 247-256.

Shah, N. H., \& Raykundaliya, N. (2010). Retailers' Pricing and Ordering Strategy for Weibull Distribution Deterioration under Trade Credit in Declining Market. Applied Mathematical Sciences, 4(21), 1011-1020.

Shah, N. H., Soni, H. N., \& Patel, K. A. (2013). Optimizing inventory and marketing policy for noninstantaneous deteriorating items with generalized type deterioration and holding cost rates. Omega, 41(2), 421-430.

Soni, H. N., \& Joshi, M. (2013). A fuzzy framework for coordinating pricing and inventory policies for deteriorating items under retailer partial trade credit financing. Computers \& Industrial Engineering, 66, 865878.

Soni, H. N., \& Patel, K. A. (2012). Optimal pricing and inventory policies for non-instantaneous deteriorating items with permissible delay in payment: Fuzzy expected value model. International Journal of Industrial Engineering Computations, 3, 281-300.

Soni, H. N., \& Patel, K. A. (2013). Joint pricing and replenishment policies for non-instantaneous deteriorating items with imprecise deterioration free time and credibility constraint. Computers \& Industrial Engineering, 66, 944-951.

Teng, J. T., Ouyang, L. Y., \& Chen, L. H. (2007). A comparison between two pricing and lot-sizing models with partial backlogging and deteriorated items. International Journal of Production Economics, 105(1), 190-203.

Tripathy, C. K., \& Pradhan, L. M. (2011). Optimal Pricing \& Ordering Policy for three parameter Weibull deterioration under trade credit. International Journal of Mathematical Analysis, 5(6), 275-284.

Tsao, Y. C., \& Sheen, G. J. (2008). Dynamic pricing, promotion and replenishment policies for a deteriorating item under permissible delay in payments. Computers \& Operations Research, 35(11), 3562-3580

Valliathal, M., \&Uthayakumar, R. (2011). Optimal pricing and replenishment policies of an EOQ model for noninstantaneous deteriorating items with shortages. International Journal of Advanced Manufacturing Technology, 54(1-4), 361-371.

Wang, Y., Zhang, J., \& Tang, W. (2013). Dynamic pricing for non-instantaneous deteriorating items. Journal of Intelligent Manufacturing, 1-12.

Wee, H. M. (1997). A replenishment policy for items with a price-dependent demand and a varying rate of deterioration. Production Planning \& Control, 8(5), 494-499.

Wee, H. M. (1999). Deteriorating inventory model with quantity discount, pricing and partial backordering. International Journal of Production Economics, 59(1), 511-518.

$\mathrm{Wu}, \mathrm{K}$. S., Ouyang, L. Y., \& Yang, C. T. (2009). Coordinating replenishment and pricing policies for noninstantaneous deteriorating items with price-sensitive demand. International Journal of Systems Science, 40(12), 1273-1281.

Yang, P. C. (2004). Pricing strategy for deteriorating items using quantity discount when demand is price sensitive. European Journal of Operational Research, 157(2), 389-397.

Yang, P. C., \& Wee, H. M. (2003). An integrated multi-lot-size production inventory model for deteriorating item. Computers \& Operations Research, 30(5), 671-682. 